\title{
The hereditary spectrum of pancreatic cancer: The Edmonton experience
}

\author{
Margaret Lilley MSc CGC CCGC ${ }^{1}$, Dawna Gilchrist MD FRCPC FCCMG ${ }^{2}$
}

\begin{abstract}
M Lilley, D Gilchrist. The hereditary spectrum of pancreatic cancer: The Edmonton experience. Can J Gastroenterol 2003;18(1):17-21.
\end{abstract}

\begin{abstract}
OBJECTIVE: Pancreatic cancer is known to aggregate in some families and has been associated with a wide variety of cancer syndromes. The authors describe their experience with pancreatic cancer and the range of associated cancer syndromes.

METHODS: The charts of all patients seen for concern of a hereditary cancer syndrome in the Cancer Genetics Clinic at the University of Alberta between 1995 and 2002 were reviewed.

RESULTS: Forty families reported a personal or family history of pancreatic cancer in the context of a possible hereditary cancer syndrome. Three additional families reported a history of pancreatitis. Twenty-four $(56 \%)$ of those families were suspected of having a hereditary breast and ovarian cancer syndrome. A further seven (16\%) were suspected of having hereditary nonpolyposis colon cancer. Only three $(7 \%)$ were believed to be at risk for a site-specific pancreatic cancer syndrome. Another three (7\%) were suspicious for hereditary pancreatitis. The remaining family histories were suggestive of Li-Fraumeni syndrome, von Hippel-Lindau syndrome or a nonspecific cancer predisposition.
\end{abstract}

CONCLUSIONS: With such a wide variety of hereditary cancer syndromes associated with pancreatic cancer, an accurate assessment of the family history is essential to determine the most appropriate cancer screening for at-risk family members and to guide any molecular testing that may be offered.

\section{Létendue héréditaire du cancer du pancréas : étude réalisée à Edmonton}

OBJECTIF : Le cancer du pancréas est connu pour se rencontrer plus souvent dans certaines familles que dans d'autres et il est associé à un large éventail de syndromes cancéreux. Les auteurs décrivent ici les résultats de leur recherche sur le cancer du pancréas et les divers syndromes cancéreux qui y sont associés.

MÉTHODE : Nous avons passé en revue tous les dossiers de patients vus à la Cancer Genetics Clinic, à l'Université de l'Alberta, entre 1995 et 2002, pour de possibles syndromes cancéreux héréditaires.

RÉSULTATS : Quarante familles ont fait état d'antécédents personnels ou familiaux de cancer du pancréas dans le contexte d'un possible syndrome cancéreux héréditaire. Trois autres familles ont déclaré des antécédents de pancréatite. Vingt-quatre (56\%) de ces familles étaient suspectes d'un syndrome cancéreux héréditaire du sein ou de l'ovaire; sept (16\%) autres, d'un cancer du côlon héréditaire, non associé à la polypose. Seulement trois $(7 \%)$ étaient considérées comme prédisposées à un syndrome cancéreux pancréatique à foyer particulier; trois autres (7\%) étaient suspectes de pancréatite héréditaire. Les derniers antécédents familiaux étaient évocateurs du syndrome de Li et Fraumeni, de la maladie de von Hippel-Lindau ou d'une prédisposition à un cancer à foyer non particulier.

CONCLUSION : Compte tenu du large éventail de syndromes cancéreux héréditaires, associés au cancer du pancréas, il est essentiel de procéder à une évaluation précise des antécédents familiaux pour déterminer le dépistage du cancer le plus approprié dans les familles prédisposées et pour orienter tout test moléculaire susceptible de leur être offert.

Key Words: Hereditary pancreatic cancer; Hereditary pancreatitis

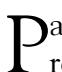
ancreatic cancer is the fifth most common cause of cancerrelated deaths in both men and women in western countries $(1,2)$. The natural history of pancreatic cancer, including disease precursors and progression, is poorly understood (3). As a result, $80 \%$ to $90 \%$ of tumours are metastatic and nonresectable when diagnosed $(1,2,4)$ and mortality is nearly $100 \%(2,3)$. It is hoped that the study of hereditary forms of pancreatic cancer may provide information that leads to new screening and therapeutic strategies (1).

Pancreatic cancer is known to aggregate in some families, and there is an increased risk for pancreatic cancer in the presence of a family history of pancreatic cancer $(3,5-7)$. The percentage of pancreatic cancer patients with a family history of pancreatic cancer ranges from $3 \%$ to $12 \%(1-3,5,7)$. The relative risk of pancreatic cancer ranges from 2.8 to $13(3,5,6)$ in the presence of a positive family history. It has even been suggested that a family history of pancreatic cancer confers more familial risk than more common cancers such as breast and colon cancer (3). Risk estimates vary among studies due to variation in the case/control populations, the number of affected individuals per family and whether factors such a smoking and other cancer history were taken into account.

The study of hereditary pancreatic cancer is particularly challenging because of the high mortality rate, with death usually occurring very shortly after diagnosis $(3,5)$. Because of the late age of onset, there is also generally a long lag between the cancers in subsequent generations $(3,5)$. Therefore, it is often difficult to obtain pathology reports or blood and tissue

\footnotetext{
${ }^{1}$ Alberta Cancer Genetics Program; ${ }^{2}$ Department of Medicine and Medical Genetics, Walter C Mackenzie Health Sciences Centre, Edmonton, Alberta

Correspondence: Dr Dawna Gilchrist, Department of Medicine and Medical Genetics, 2E3.28 Walter C Mackenzie Health Sciences Centre, Edmonton, Alberta T6G 2R7. Telephone 780-407-7290, fax 780-407-2680, e-mail dawna.gilchrist@ualberta.ca

Received for publication September 9, 2003. Accepted November 7, 2003
} 
TABLE 1

\section{Referral criteria}

\begin{tabular}{l}
\hline Individual/family with diagnosed hereditary syndrome on clinical \\
grounds (eg, familial adenomatous polyposis) \\
2. Individual/family with diagnosed hereditary syndrome on molecular \\
grounds (eg, known mutation in breast and ovarian cancer \\
syndrome [BRCA] 1 or 2 ) \\
3. Individual/family meeting standard referral criteria for specific \\
syndromes (eg, BRCA, hereditary nonpolyposis colon cancer, \\
von Hippel-Lindau). For pancreatic cancer alone, this would be \\
(minimal) history of two first degree relatives with pancreatic cancer
\end{tabular}

samples on more than one affected family member $(7,8)$. With a wide variety of hereditary cancer syndromes associated with pancreatic cancer, an accurate assessment of the family history can help determine what cancer surveillance is recommended for at-risk family members and what molecular testing may be offered.

\section{THE EDMONTON CANCER GENETICS CLINIC EXPERIENCE}

The Edmonton Cancer Genetics Clinic was formally established in 1997, and over 600 patients and families have been referred for personal and family history of cancer. This service clinic offers counseling and potential testing to individuals suspected of having a hereditary cancer syndrome and is not targeted for any specific kind of hereditary cancer. The most common reason for referral is for concern of the hereditary breast ovarian cancer syndrome (BRCA) or a familial colon cancer syndrome.

The catchment area for the clinic is northern Alberta, including some referrals from northeastern British Columbia and the Northwest Territories. This encompasses a population of approximately 1.5 million people, with Edmonton being the major referral base for the entire area, particularly for cancer. Referrals to our clinic are accepted from family physicians or specialists. The latter group includes oncologists and a full variety of specialists and subspecialists in surgery, gynecology and medicine. The Edmonton Cancer Genetics Clinics is the only resource for cancer genetics counseling and testing in the catchment area. Therefore, although we cannot be sure of what percentage of familial cancer cases are referred, if they are referred, they are referred to us.

We reviewed the charts of all patients seen in the Cancer Genetics Clinic at the University of Alberta between 1995 and 2002 for any concern of familial cancer (Table 1). Forty families reported a personal or family history of pancreatic cancer (Table 2). Three additional families reported a history of pancreatitis. Risk assessment was performed by a medical geneticist after a review of the family history and pathology reports, when available. Pathology reports confirming pancreatic cancer were available for 18 of the families. Many histories of pancreatic cancer could not be confirmed because of lack of records or lack of access to records. However, we assume that verbal history of pancreatic cancer is more specific than generic history for abdominal or gynecological cancer.

The family histories were consistent with a variety of hereditary cancer syndromes including: BRCA2, hereditary
TABLE 2

The Edmonton Cancer Genetics Clinic experience

\begin{tabular}{lc}
\hline Suspected hereditary syndrome & Number of families (\%) \\
\hline Hereditary breast and ovarian cancer (BRCA2) & $24 / 43(56)$ \\
Hereditary nonpolyposis colon cancer (HNPCC) & $7 / 43(16)$ \\
Pancreatic cancer syndrome & $3 / 43(7)$ \\
Hereditary pancreatitis & $3 / 43(7)$ \\
BRCA2 or HNPCC & $2 / 43(4.7)$ \\
Li Fraumeni syndrome & $1 / 43(2.3)$ \\
Li Fraumeni-like syndrome or BRCA2 & $1 / 43(2.3)$ \\
von Hippel-Lindau & $1 / 43(2.3)$ \\
Nonspecific cancer syndrome & $1 / 43(2.3)$ \\
\hline
\end{tabular}

nonpolyposis colon cancer (HNPCC), von Hippel-Lindau (vHL), Li Fraumeni (LFS) or LFS-like syndrome and site-specific pancreatic cancer. Twenty-four of the 40 families were suspicious for BRCA. Seven families had histories suggestive of HNPCC. Two families were felt to be equally likely to have either HNPPC or BRCA2. Three family histories were suggestive of a site-specific pancreatic cancer syndrome. Three families had histories suggestive of hereditary pancreatitis. One family history was suggestive of LFS. Another family was felt to be equally likely to have either LFS or BRCA2. One large family was diagnosed with vHL syndrome. In one family, although the family history strongly suggested a hereditary cancer syndrome, the history was not indicative of a specific syndrome. Therefore, in our experience, site-specific pancreatic cancer is rare and pancreatic cancer is more likely to be seen as part of another hereditary cancer syndrome, such as BRCA2 or HNPCC.

\section{DISCUSSION}

Hereditary syndromes associated with pancreatic cancer There are a wide variety of syndromes that have been associated with pancreatic cancer (Table 3).

Hereditary pancreatic cancer: Reports of multiple cases of pancreatic cancer, in subsequent generations, suggests that there is a syndrome of site-specific pancreatic cancer $(3,5,6)$. Analysis of the kindreds suggests an autosomal dominant mode of inheritance with reduced penetrance $(3,6)$. Hereditary pancreatic cancer has also been associated with a younger age of onset than sporadic cases. Ghadirian et al (5) found a relative risk of 2 in relatives of patients with pancreatic cancer below the age of 60 years compared with a relative risk of 1.4 for relatives of patients over the age of 60 years. Computerized segregation analysis of pancreatic cancer supported the inheritance of a rare autosomal dominant allele with incomplete penetrance, where the allele is associated with a younger age of onset (4).

Hereditary pancreatitis: Hereditary pancreatitis is an autosomal dominant condition with $80 \%$ penetrance and variable expressivity $(1,9)$. Hereditary pancreatitis may account for $1 \%$ to $6 \%$ of all pancreatitis $(1,2)$. A history of pancreatitis is associated with an increased risk for pancreatic cancer with risk estimates variably reported as $4 \%$ cumulative risk over 25 years (9), $40 \%$ risk to age 70 years (2), $30 \%$ to $40 \%$ lifetime risk (9) and relative risk of 2 to $16(1,2)$.

Some forms of hereditary pancreatitis have been associated with a germline mutation $\mathrm{R} 117 \mathrm{H}$ in the cationic trypsinogen 
TABLE 3

Hereditary cancer syndromes associated with pancreatic cancer

\begin{tabular}{|c|c|c|c|}
\hline Hereditary syndrome & $\begin{array}{l}\text { Inheritance and } \\
\text { other features }\end{array}$ & $\begin{array}{c}\text { Most commonly } \\
\text { associated cancers }\end{array}$ & $\begin{array}{c}\text { Associated } \\
\text { genes/mutations }\end{array}$ \\
\hline $\begin{array}{l}\text { Hereditary pancreatic } \\
\text { cancer syndrome }\end{array}$ & $\begin{array}{c}A D, \text { reduced penetrance, } \\
\text { younger age of onset }\end{array}$ & Pancreatic & None identified \\
\hline Hereditary pancreatitis* & $A D, 80 \%$ penetrance & Pancreatic & $\begin{array}{l}\text { R117H mutation in gene } \\
\text { PRSS1/TRY1 }\end{array}$ \\
\hline $\begin{array}{c}\text { Multiple endocrine } \\
\text { neoplasia } 1^{\dagger}\end{array}$ & $A D$, variable expressivity & $\begin{array}{l}\text { Parathyroid, pancreatic, } \\
\text { pituitary }\end{array}$ & MEN1 \\
\hline $\begin{array}{l}\text { Familial adenomatous } \\
\text { polyposis* }^{*}\end{array}$ & $A D$, nearly complete penetrance & $\begin{array}{l}\text { Colon, upper gastrointestinal } \\
\text { tract, soft tissue }\end{array}$ & $A P C$ \\
\hline $\begin{array}{l}\text { Familial atypical multiple } \\
\text { mole melanoma }\end{array}$ & $A D$, reduced penetrance & Melanoma, pancreatic & CDKN2, p16 \\
\hline $\mathrm{BRCA} 2^{*}$ & $A D$, reduced penetrance & Breast, ovarian, & $B R C A 2$ \\
\hline Peutz-Jeghers syndrome & $A D$, reduced penetrance & $\begin{array}{l}\text { Pancreatic, gastrointestinal, } \\
\text { gynecological }\end{array}$ & STK11/LKB1 \\
\hline Ataxia telangiectasia* & $\mathrm{AR}$, carriers at increased risk for cancer & Pancreatic, breast, stomach & ATM \\
\hline Hereditary nonpolyposis colon cancer* & $A D$, reduced penetrance & $\begin{array}{l}\text { Colon, endometrial, ovarian, } \\
\text { urinary tract }\end{array}$ & $M S H 2, M L H 1$ \\
\hline Li Fraumeni syndrome $^{\dagger}$ & $A D$, reduced penetrance & Sarcoma, breast, leukemia & TP53 \\
\hline von Hippel-Lindau disease* & $A D$, reduced penetrance & $\begin{array}{l}\text { Hemangioblastomas, renal cell, } \\
\text { pancreatic }\end{array}$ & $V H L$ \\
\hline
\end{tabular}

*Testing available; †Known mutation testing only. AD Autosomal dominant; AR Autosomal recessive; BRCA2 Breast and ovarian cancer syndrome

gene PRSS1/TRY1 (1). However, only about $60 \%$ to $70 \%$ of hereditary pancreatitis families are linked to this locus (7).

Multiple endocrine neoplasia type 1: Multiple endocrine neoplasia type I (MEN1) is an autosomal dominant disorder characterized by tumours of the parathyroid, pancreatic islets and the anterior pituitary (10-12). Parathyroid, pancreatic and pituitary tumours occurred in $95 \%, 41 \%$ and $30 \%$ of the patients, respectively (11). MEN1 has variable expressivity and considerable genetic heterogeneity (12). Patients with MEN1 are also at risk for gastrinomas, which are thought to occur predominantly in the pancreas and to be multicentric (10). Pancreatic endocrine tumours reports vary widely from study to study $(10,12)$.

Familial adenomatous polyposis: An increased risk for pancreatic cancer has been associated with familial adenomatous polyposis. Chappuis et al (1) examined 197 familial adenomatous polyposis pedigrees and found a $4.46 \%$ risk of pancreatic cancer. DiMagno noted that the corresponding absolute risk was low: 21/100,000 person years (2)

Familial atypical multiple mole melanoma: Familial atypical multiple mole melanoma (FAMMM) is an autosomal dominant syndrome with incomplete penetrance. The clinical manifestations include multiple nevi, multiple atypical nevi, multiple malignant melanoma and an increased risk for other cancers, including pancreatic cancer (1). Pancreatic cancer is the second most common cancer in this syndrome, after melanoma, with an observed to expected ratio of 13.4 (1).

FAMMM has been associated with mutations in the cell cycle inhibitor gene p16 $(1,2)$. Mutations in the cyclindependent kinase inhibitor 2 impair the function of the p16 protein and have also been implicated in FAMMM (3). FAMMM families with a p16 mutation were found to have a 22- to 23-fold increased risk for pancreatic cancer compared to FAMMM families without a p16 mutation $(1,5,7)$.

BRCA2: In addition to being at increased risk for breast and ovarian cancer, studies have shown that individuals who carry
BRCA2 mutations are at increased risk for pancreatic cancer $(1,5,7,8)$. BRCA1 mutations have not been implicated in pancreatic cancer (5). The Breast Cancer Linkage Consortium estimated the relative risk to be 5.5 for pancreatic cancer to age 65 years in BRCA2 mutation carriers (5). A study of families with familial pancreatic cancer found a $10 \%$ incidence of BRCA2 germline mutations (7). The penetrance of pancreatic cancer in BRCA2 mutation carriers is significantly lower than breast cancer (8). Phelan et al (13) found only four pancreatic cancers compared to 48 breast cancers among eight families with germline BRCA2 mutations.

Peutz-Jeghers syndrome: Peutz-Jeghers syndrome (PJS) is an autosomal dominant syndrome characterized by nonneoplastic hamartomatous polyps in the gastrointestinal tract and by pigmented macules of the lips, buccal mucosa and digits (14). Pancreatic cancer is the most common cancer reported in PJS patients $(1,14)$. Other associated cancers include gastrointestinal, gynecological, lung, breast, thyroid and basal cell (14). Individuals with PJS have a 100 - to 132 -fold excess risk of pancreatic cancer compared with the general population (1) and an $11 \%$ lifetime risk of developing pancreatic cancer (7).

Germline mutations in the STK11/LKB1 gene are responsible for PJS $(1,14)$. Both germline and somatic mutations in STK11/LKB1 have been reported in pancreatic cancer (14). Therefore, STK1/LKB1 is postulated to play a causal role in the genesis of both sporadic and familial pancreatic cancer (14).

Ataxia telangiectasia: Ataxia telangiectasia (AT) is a progressive neurological disorder in which there is a varied immune dysfunction (15). Individuals with AT have an excess sensitivity to ionizing radiation and are subsequently at increased risk for various cancers (15). Although AT is an autosomal recessive condition, there is an elevated incidence of cancer among AT heterozygotes, or carriers $(1,16)$. Breast, prostate, stomach, melanoma, lymphoma, leukemia and pancreatic cancers have all been reported in excess in AT carriers (16). 
HNPCC: HNPCC is associated with an increased risk of colorectal cancer and other cancers, such as endometrium, stomach, ovary, biliary and urinary tracts and small intestine (1). Pancreatic cancer is sometimes included in the tumor spectrum of HNPCC (1) and there is conflicting opinion regarding the association between HNPCC and pancreatic cancer $(1,3,7)$. Lynch et al $(3)$ hypothesized that pancreatic cancer is likely part of the HNPCC spectrum; however, the genetic heterogeneity is so great that statistical analysis of the aggregate families from any particular resource will not necessarily elucidate a statistical significance. Other authors suggest that the presence of pancreatic cancer in HNPCC kindreds is a chance finding, possibly related to ascertainment bias (1). To date, no phenotype/genotype correlation has been established for any cancers associated with HNPCC (1).

LFS: LFS is an autosomal dominantly inherited syndrome with a predisposition to early-onset sarcoma, breast cancer and other neoplasms (1). Adenocarcinoma of the pancreas may also be included in the tumour spectrum of this syndrome. Chappuis et al (1) reported that pancreatic cancer accounted for only $1 \%$ of all the reported tumours in a sample of LFS patients.

vHL: vHL disease is a relatively rare autosomal dominantly inherited multitumour syndrome (17). The lesions associated with $\mathrm{vHL}$ include hemangioblastomas in the central nervous system and retina, renal cell carcinomas, pheochromocytomas, pancreatic tumours, epididymal cystadenomas and endolymphatic sac tumours carcinoid tumours (17). Hammel et al (18) reported that $77 \%$ of patients with vHL have some pancreatic involvement. Imaging studies reveal that $12 \%$ to $17 \%$ of vHL patients have pancreatic neuroendocrine tumours $(17,19)$. Individuals with $\mathrm{vHL}$ develop tumours at a younger age than individuals with the same, but sporadic, tumours, and are at increased risk for multifocal tumours (17).

\section{Sporadic mutations}

Mutations in many of the genes implicated in inherited pancreatic cancer syndromes are also found in sporadic pancreatic cancer tumour cells, implying that they are important in both hereditary and sporadic pancreatic cancer $(1,7,8,20)$ (Table 4). Rozenblum et al (20) studied 42 pancreatic adenocarcinomas for somatic genetic alterations. They found that over $75 \%$ of the tumours had mutations in three or more genes including the oncogene K-ras and tumour repressors p16, p53 and DPC4. $\mathrm{K}$-ras, which is the most frequently mutated gene in sporadic pancreatic cancer, has not been described as an inherited cancer predisposing gene (1). Eighty-three per cent of sporadic pancreatic tumours were found to have a distinctive genetic pattern which includes activation of the K-ras oncogene and inactivation of $p 16$, generally also accompanied by alterations in the $p 53$ gene (76\% of tumours) (20).

\section{Environmental factors}

Dietary factors: Several dietary factors have been associated with an increased risk for pancreatic cancer including salted or smoked foods, saturated fats, red meats, carbohydrates, salt and refined sugar $(1,5)$. Fresh fruits and vegetables, dietary fiber and vitamin $C$ have been reported to have a protective effect against pancreatic cancer $(1,5)$. However, a vegetarian diet was not found to have a protective effect (3). While vitamin C was found to have a protective effect (1), neither betacarotene nor vitamin $\mathrm{E}$ was found to affect the risk of pancreatic cancer. In addition, neither alcohol nor coffee intake was
TABLE 4

Frequency of somatic mutations in pancreatic cancers

\begin{tabular}{lc}
\hline Gene & $\begin{array}{c}\text { Frequency of somatic mutations } \\
\text { in pancreatic cancers (\%) }\end{array}$ \\
\hline$p 16$ & $80-95$ \\
K-ras & 90 \\
$p 53$ & $50-70$ \\
$D P C 4$ & 53 \\
$B R C A 2$ & 7 \\
LKB1/STK11 & 4 \\
MKK4 & 4 \\
$T G F B-R 1$ and $T G F B-R 2$ & $<5$ combined \\
$R B 1$ genes & $<5$ \\
$A L K 4$ & $<3$
\end{tabular}

found to be associated with an increased risk for pancreatic cancer $(1,3)$.

Obesity: An excess of pancreatic cancer has been reported in obese individuals $(2,3,9)$. Pancreatic cancer has been specifically linked to increased caloric intake and to increased body mass index $(3,9)$. Obesity has been linked to other cancers, such as biliary and reproductive system cancers (9).

Tobacco: Cigarette smoking is the most important and consistent environmental risk factor for pancreatic cancer $(3,5,9)$. Both men and women with heavy cigarette consumption have a two- to three-fold higher risk for pancreatic cancer that nonsmokers $(5,9)$. The greater the cigarette consumption, the higher the risk for pancreatic cancer (5). Klein et al (7) estimated that cigarette smoking accounts for $25 \%$ to $30 \%$ of pancreatic cancers.

Occupation: It has been difficult to define occupational risk factors for pancreatic cancer accurately; however, occupational exposure is estimated to account for only $5 \%$ of all cases of pancreatic cancer (9). DiMagno (2) purports that the environmental risk associated with pancreatic cancer may be related to exposure to aromatic amines. Cigarette smoke, cooked meat and smoked fish contain aromatic amines and have been associated with an increased risk for pancreatic cancer $(1,2,7)$. Occupations with an increased exposure to aromatic amines, such as chemists and petrochemical and rubber workers, have been associated with an increased risk for pancreatic cancer (2). Exposure to metalworking fluids may also be associated with an increased risk for pancreatic cancer (1).

Chronic pancreatitis: A history of chronic pancreatitis is associated with an increased risk for pancreatic cancer. Risk estimates for pancreatic cancer include a relative risk of 2.04 (1), a $4 \%$ to $5 \%$ cumulative 25 -year risk $(1,9)$ and a 15 -fold increased risk (9).

Insulin dependent diabetes mellitus: A meta-analysis has suggested that a history of five or more years of insulin dependent diabetes mellitus is associated with a two-fold increased risk for pancreatic cancer (7). However, the onset of diabetes may also be an early manifestation of pancreatic cancer (1). Therefore, the relationship between insulin dependent diabetes mellitus and pancreatic cancer is still quite controversial. Some studies strongly suggest a causal relationship between long-standing diabetes and pancreatic cancer while other studies have not found such a link (9). 


\section{SUMMARY}

Pancreatic cancer is one of the leading causes of cancer death in North America and has one of the highest mortality rates (5). Our limited understanding of the etiology and natural history of this cancer makes screening for, and treatment of, pancreatic cancer challenging. Information obtained from the study of hereditary forms of pancreatic cancer may lead to new treatment and surveillance strategies (1).

\section{REFERENCES}

1. Chappuis PO, Ghadirian P, Foulkes WD. The role of genetic factors in the etiology of pancreatic adenocarcinoma: an update. Cancer Invest 2001;19:65-75.

2. DiMagno EP. Pancreatic cancer: Clinical presentation, pitfalls and early clues. Ann Oncol 1999;10(Suppl 4):140-2.

3. Lynch HT, Brand RE, Lynch JF, Fusaro RM, Kern SE. Hereditary factors in pancreatic cancer. J Hepatobiliary Pancreat Surg 2002;9:12-31.

4. Klein AP, Beaty TH, Bailey-Wilson JE, Brune KA, Hruban RH, Petersen GM. Evidence for a major gene influencing risk of pancreatic cancer. Genet Epidemiol 2002;23:133-49

5. Ghadirian P, Liu G, Gallinger S, et al. Risk of pancreatic cancer among individuals with a family history of cancer of the pancreas. Int J Cancer 2002;97:807-10.

6. Tersmette AC, Petersen GM, Offerhaus GJA, et al. Increased risk of incident pancreatic cancer among first-degree relatives of patients with familial pancreatic cancer. Clin Cancer Res 2001;7:738-44.

7. Klein AP, Hruban RH, Brune KA, Petersen GM, Goggins M. Familial pancreatic cancer. Cancer Journal 2001;7:266-73.

8. Goggins M, Schutte M, Lu J et al. Germline BRCA2 gene mutations in patients with apparently sporadic pancreatic carcinomas. Cancer Res 1996;56:5360-4.

9. Lowenfels AB, Maisonneuve P. Epidemiologic and etiologic factors of pancreatic cancer. Hematol Oncol Clin North Am 2002;16:1-16.

10. Pipeleers-Marichal M, Somers G, Willems G, et al. Gastrinomas in the duodenums of patients with multiple endocrine neoplasia type 1 and the Zollinger-Ellison syndrome. N Engl J Med 1990;322:723-7.

11. Trump D, Farren B, Wooding C, et al. Clinical studies of multiple endocrine neoplasia type 1 (MEN1). Q J Med 1996;89:653-69.

12. Kouvaraki MA, Lee JE, Shapiro SE, et al. Genotype-phenotype analysis in multiple endocrine neoplasia type 1. Arch Surg 2002;137:641-7.

13. Phelan CM, Lancaster JM, Tonin P, et al. Mutation analysis of the BRCA2 gene in 49 site-specific breast cancer families. Nat Genet 1996;13:120-2.

14. Su GH, Hruban RH, Bansal RK et al. Germline and somatic mutations of the STK11/LKB1 Peutz-Jeghers gene in pancreatic and biliary cancers. Am J Pathol 1999;154:1835-40.

15. Swift M, Chase CL, Morrell D, Cancer predisposition of ataxiatelangiectasia heterozygotes. Cancer Genet Cytogenet 1990;46:21-7.

16. Morrell D, Chase CL, Swift M. Cancers in 44 families with ataxiatelagiectasia. Cancer Genet Cytogenet 1990;50:119-23.

17. Sano T, Horiguchi H. Von Hippel-Lindau disease. Microsc Res Tech 2003;60:159-64

18. Hammel PR, Vilgrain V, Terris B, et al. Pancreatic involvement in von Hippel-Lindau disease. Gastroenterology 2000;119:1087-95.

19. DeLellis, RA. The hereditary forms of pancreatic neuroendocrine tumors. Adv Anat Pathol 1999;6:149-53.

20. Rozenblum E, Schutte M, Goggins M, et al. Tumor-suppressive pathways in pancreatic carcinoma. Cancer Res 1997;57:1731-4. 


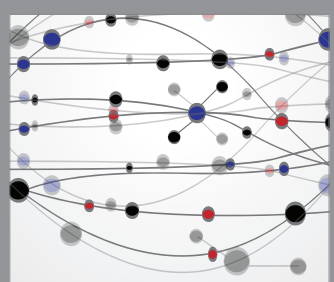

The Scientific World Journal
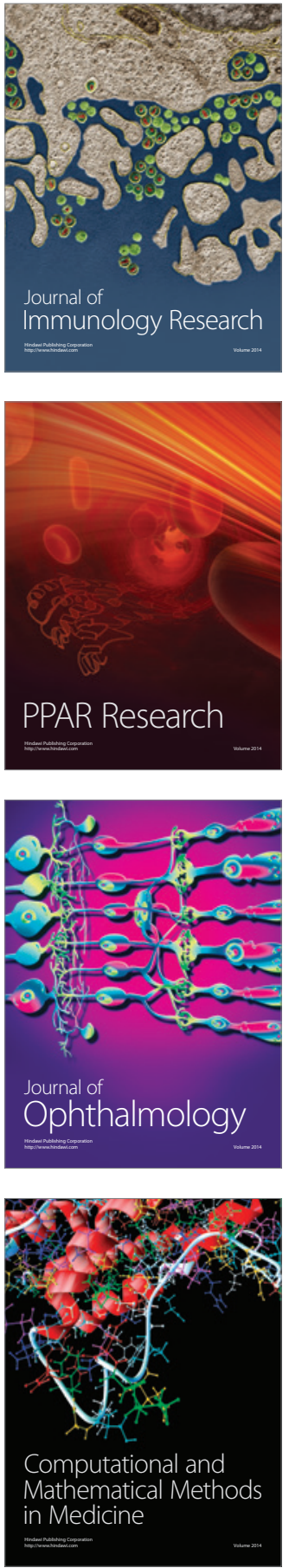

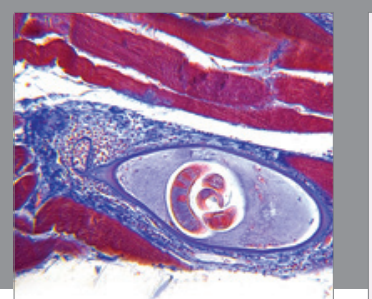

Gastroenterology Research and Practice

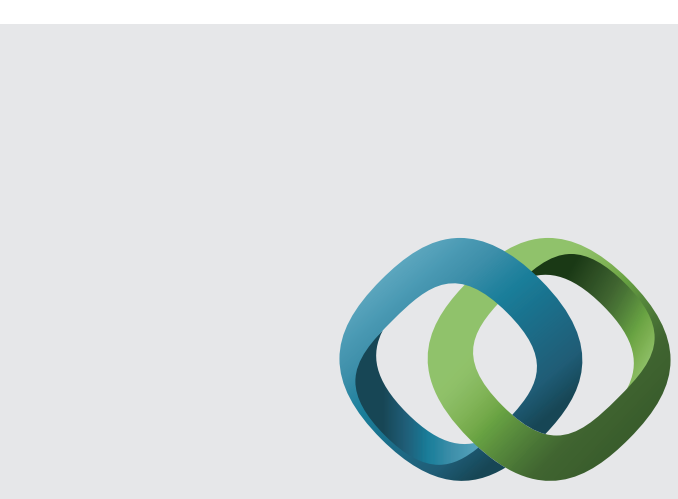

\section{Hindawi}

Submit your manuscripts at

http://www.hindawi.com
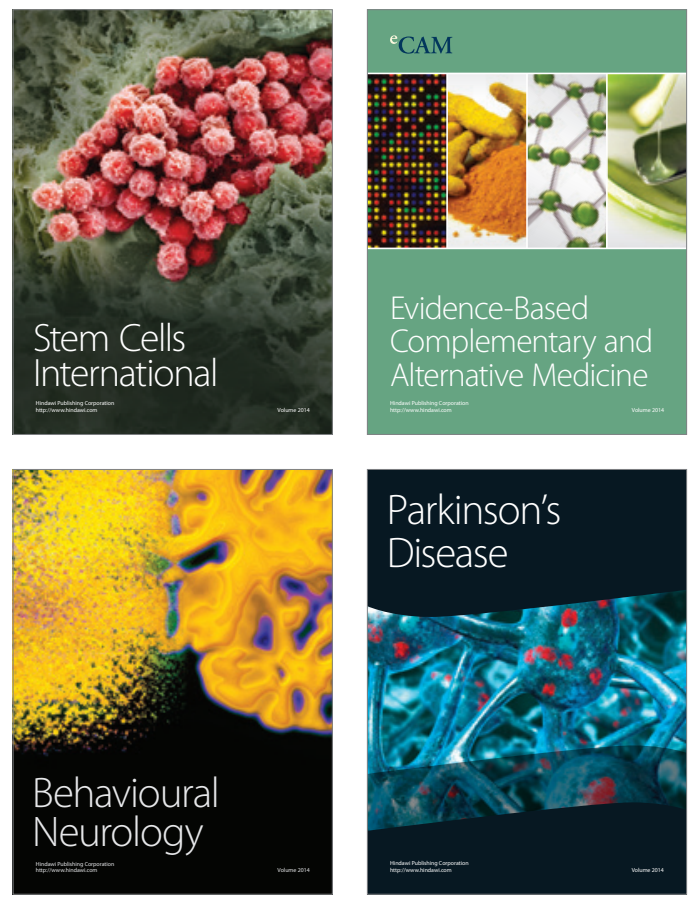
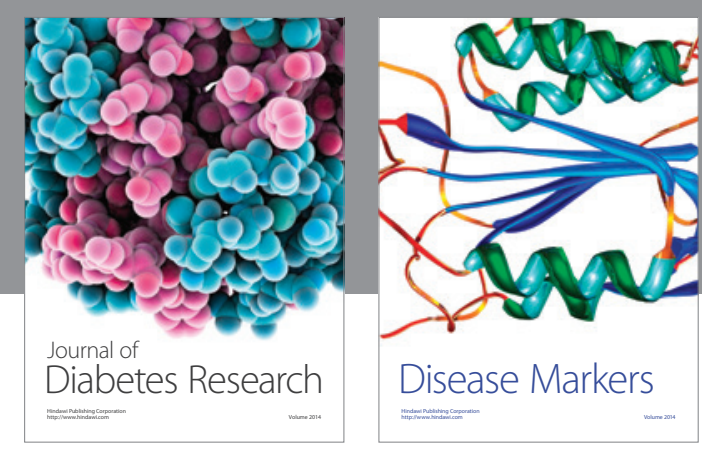

Disease Markers
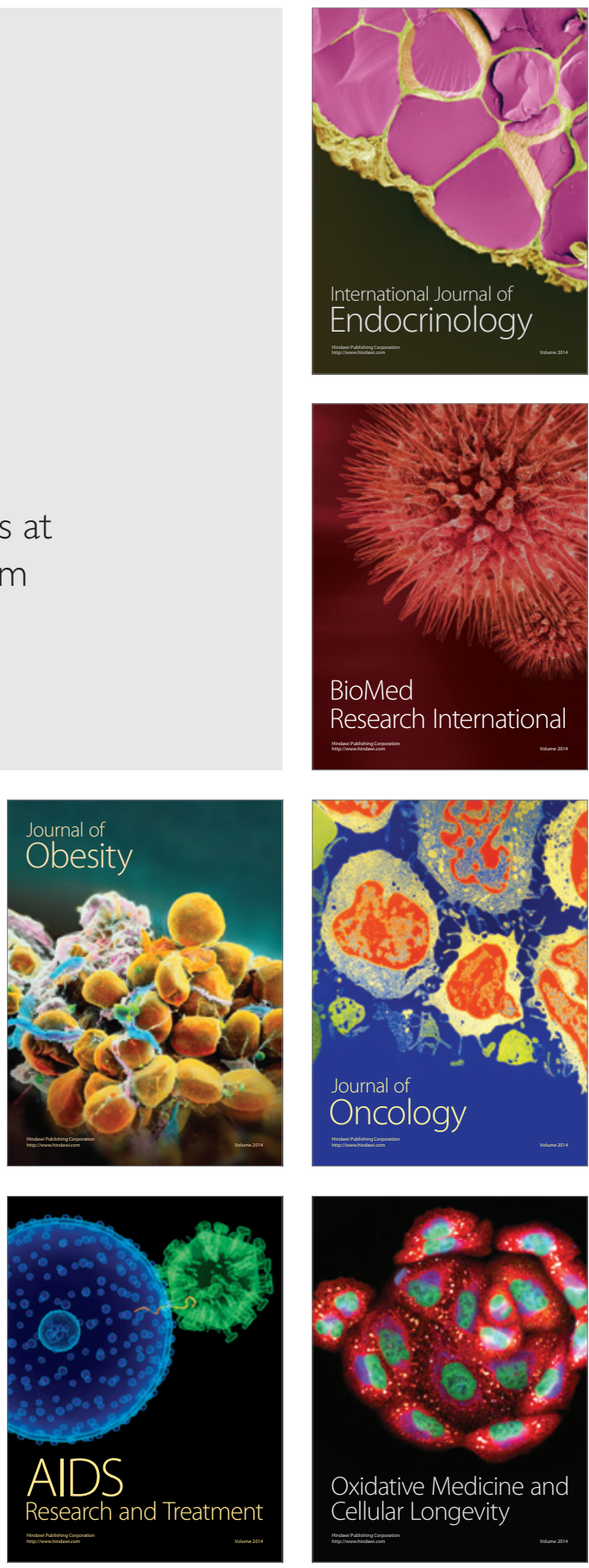